\title{
Influence of Sea Water Aging on the Mechanical Behaviour of Acrylic Matrix Composites
}

\author{
Davies Peter ${ }^{1,{ }^{*}}$, Le Gac Pierre-Yves ${ }^{1}$, Le Gall Maelenn ${ }^{1}$ \\ ${ }^{1}$ IFREMER, Centre Bretagne, Marine Structures Laboratory, 29280 Plouzané, France \\ * Corresponding author : Peter Davies, email address : peter.davies@ifremer.fr
}

\begin{abstract}
:
A new matrix resin was recently introduced for composite materials, based on acrylic resin chemistry allowing standard room temperature infusion techniques to be used to produce recyclable thermoplastic composites. This is a significant advance, particularly for more environmentally-friendly production of large marine structures such as boats. However, for such applications it is essential to demonstrate that composites produced with these resins resist sea water exposure in service. This paper presents results from a wet aging study of unreinforced acrylic and glass and carbon fibre reinforced acrylic composites. It is shown that the acrylic matrix resin is very stable in seawater, showing lower property losses after seawater aging than those of a commonly-used epoxy matrix resin. Carbon fibre reinforced acrylic also shows good property retention after aging, while reductions in glass fibre reinforced composite strengths suggest that specific glass fibre sizing may be required for optimum durability.
\end{abstract}

Keywords : Acrylic, Thermoplastic, Infusion, Seawater, Immersion

1. Introduction

The marine industry has traditionally used large quantities of glass fibre reinforced thermoset polyester resin, particularly for boat and ship construction [1-3]. At the end of the twentieth century as environmental and health and safety legislation became stricter there was a move to low styrene emission resins and closed mould manufacture. Today low pressure impregnation techniques such as vacuum infusion are widely used for boat-building, with considerable benefits for workers' health. However, the matrix resins are still thermosets and there is a major problem with end-of-life disposal of composite boats. In 2008 there were estimated to be over 500,000 small composite boats in France with an average age of 23 years [4]. Their average lifetime is 30 years, so large numbers of boats must be disposed of in the next few years. Unfortunately landfill is the cheapest solution, resulting in loss of valuable materials and energy. In order to improve the environmental footprint of marine composites in the future there have been various matrix polymer developments recently, including partially or fully bio-sourced thermoset resins and biodegradable polymers [5]. Another way to reduce environmental impact is to switch to thermoplastic polymers, which offer the possibility for recycling and re-use. However, up to now these have required a step change in manufacturing technology, needing high temperatures (typically at least $150-200^{\circ} \mathrm{C}$ for polymers such as polypropylene), which are not usually available in boatyards. In 2014 Arkema introduced a liquid acrylic resin suitable for infusion. In addition to the acrylic monomer, the resin contains a 
peroxide catalyst to initiate the polymerization and an accelerator agent to activate the catalyst. This low viscosity liquid monomer (100-500 cPs) allows impregnation of the fibre reinforcement by methods such as vacuum infusion, and then the production of a recyclable thermoplastic by radical polymerization in the mould. This offers great potential for the production of marine structures, and a carbon fibre reinforced racing yacht prototype was manufactured recently [6], but there are no data currently available to assess the durability of composites based on such a matrix in a marine environment. Acrylic thermoplastics are used in some marine applications, for underwater viewglasses for example, and there has been some work to study their behavior in water [7]. Small strain properties were shown not to be sensitive to water, while fracture toughness increased significantly when water was present. Thermosetting modified acrylic matrix resins (Modar ${ }^{\mathrm{TM}}$ ) have also been studied for composite applications in the past, though these are based on polyurethanes in a methyl methacrylate solvent monomer, they are sometimes used where improved fire behavior compared to polyesters is required [8,9]. It is also worth noting that there is a large body of literature concerning moisture effects on commercial acrylic resins for dentistry applications, e.g. $[10,11]$.

The evaluation of marine durability of composites has been described in recent publications such as $[12,13]$, and involves several steps depending on the end application, but the first is usually to examine the sea water diffusion kinetics and the second is to assess the influence of saturation in sea water on mechanical properties. Some data are available for several common marine materials such as glass/polyester used in small boats and traditional military construction [14-17], glass/epoxy used in larger structures [14] and vinylester used in recent civil engineering and military construction [1619]. This database, and various other studies in which tap water or distilled water were used for aging, allows new materials to be compared to materials for which there is a wider experience. Subsequent durability evaluation steps may require creep or cyclic loading and coupling between water diffusion and mechanical loads, but in this paper only the first two steps will be described. Unreinforced acrylic matrix, glass fibre and carbon fibre reinforced composites have been aged in natural sea water for up to 18 months, and mechanical properties have been evaluated at and beyond saturation. Results are discussed with respect to the aging behavior of other marine composites.

\section{Materials}

Unreinforced matrix plates $2.7 \mathrm{~mm}$ thick were cast from Elium ${ }^{\text {TM }} 190$ resin mixed with benzoyl peroxide. These are transparent so defects are easy to detect; none were observed here.

One panel of E-glass fibre reinforced composite with 3 layers of $830 \mathrm{~g} / \mathrm{m}^{2} 0 / 90^{\circ}$ woven reinforcement was produced in a commercial boatyard by infusion with the RT300 Elium ${ }^{\mathrm{TM}}$ grade, initiated with 1 part of Luperox ${ }^{\mathrm{TM}}$ ANS50G. This reinforcement is a $2 \times 2$ taffeta weave which is widely used in traditional boat-building with polyester resins. No special sizing was used for the acrylic resin. The panel was cut in two directions, in the fibre $\left(0^{\circ}\right)$ direction and at $45^{\circ}$, in order to produce specimens with two orientations for testing.

Two series of carbon/epoxy plates were produced by Arkema using infusion with the new Elium ${ }^{\text {TM }}$ 150 and 2 parts of Perkadox ${ }^{\mathrm{TM}}$ CH50. Quadriaxial (QX) plates were composed of 3 layers of stitched non-crimp fabric biaxial $600 \mathrm{~g} / \mathrm{m}^{2}$ reinforcement. These were laid up to form a $90 / 0 / 45 /-45 / 0 / 90^{\circ}$ 
stacking sequence. Plates were also produced with a $\pm 45^{\circ}$ layup using 3 biaxial layers superposed at $\pm 45^{\circ}$. These carbon reinforced plates were around $1.5 \mathrm{~mm}$ thick.

The glass transition temperature, $\mathrm{Tg}$, was measured for each material by DSC, with TA Instruments Q200 equipment and a heating ramp of $10^{\circ} \mathrm{C} /$ minute from 0 to $200^{\circ} \mathrm{C}$. Densities were measured using a helium gas pycnometer (model AccuPycll 1340), composite fibre contents were estimated from a rule of mixtures using these values assuming no porosity (density of glass and carbon fibres were taken to be 2.62 and 1.80 respectively).

Table 1 summarizes the properties of the materials tested.

\begin{tabular}{|l|c|c|c|c|}
\hline Material & Thickness, $\mathrm{mm}$ & Density, $\mathrm{kg} / \mathrm{m}^{3}$ & $\begin{array}{c}\text { Estimated Fibre } \\
\text { content } \mathrm{V}_{\mathrm{f}}\end{array}$ & $\mathrm{T}_{\mathrm{g}}{ }^{\circ}{ }^{\circ} \mathrm{C}$ unaged \\
\hline Acrylic Resin & $2.66(0,02)$ & $1190(10)$ & - & $116(1)$ \\
\hline Glass/Acrylic & $2.93(0.14)$ & $2040(14)$ & 0.58 & $112(2)$ \\
\hline Carbon/Acrylic & & & & \\
QX & $1.46(0.09)$ & $1520(20)$ & 0.54 & $98(2)$ \\
$\pm 45^{\circ}$ & $1.73(0.06)$ & $1500(13)$ & 0.52 & $96(2)$ \\
\hline
\end{tabular}

Table 1. Materials tested.

\section{Experimental Methods}

Aging was performed by immersion in natural sea water, pumped from the Brest Estuary into 170 litre tanks maintained at different temperatures. The sea water is continuously renewed. Coupons (50 mm $\times 50 \mathrm{~mm}$ ), 3 for each condition, were immersed at 25,40 and $60^{\circ} \mathrm{C}$. Tension specimens (type $1 \mathrm{~A}$ dog-bone in ISO 527, $152 \mathrm{~mm}$ long with $10 \mathrm{~mm}$ central section cut from the resin plate using a high pressure water jet, $20 \mathrm{~mm}$ wide parallel sided specimens for the composites cut using a diamond tipped saw) were also placed in the tanks. The resin and carbon composites were immersed at 25, 40 and $60^{\circ} \mathrm{C}$, glass reinforced composites only at $60^{\circ} \mathrm{C}$. Water temperatures were recorded continuously and found to be within $\pm 2^{\circ} \mathrm{C}$ for the duration of the tests, which lasted up to 18 months. All coupons and specimens were dried to constant weight in an oven at $60^{\circ} \mathrm{C}$ before immersion. During aging the coupons were removed regularly from the tanks for weighing, in order to determine weight gain with immersion time. Altogether 60 resin and 120 composite tensile specimens were tested in this study, Table 2 summarizes the aging conditions.

\begin{tabular}{|l|c|c|c|}
\hline & $25^{\circ} \mathrm{C}$ & $40^{\circ} \mathrm{C}$ & $60^{\circ} \mathrm{C}$ \\
\hline Acrylic resin & $16,77,365$ & $16,77,365$ & $16,77,365$ \\
\hline $\begin{array}{l}\text { Carbon/Acrylic } \\
\left(\text { QX and } \pm 45^{\circ}\right)\end{array}$ & 365 & 365 & $16,77,365$ \\
\hline $\begin{array}{l}\text { Glass/Acrylic } \\
\left(\text { Woven } 0 / 90^{\circ} \text { and } \pm 45^{\circ}\right)\end{array}$ & - & - & $69,190,545$ \\
\hline
\end{tabular}

Table 2. Summary of immersion conditions (days in sea water). 6 specimens for each case.

In each case six specimens were removed from water, 3 were tested wet in the laboratory at $20^{\circ} \mathrm{C}$ (specimens were kept in water at $20^{\circ} \mathrm{C}$ before testing and tested within one hour after removal from the tank), and 3 were dried in an oven at $60^{\circ} \mathrm{C}$ until constant weight before testing at $20^{\circ} \mathrm{C}$.

Tests were performed on resin and composite specimens in tension under displacement control at 2 $\mathrm{mm} /$ minute. Quasi-isotropic and $0 / 90^{\circ}$ specimens were loaded in the $0^{\circ}$ fibre direction, $\pm 45^{\circ}$ 
specimens were loaded at $45^{\circ}$ to the fibres, as recommended by ASTM D3518 to determine in-plane shear properties. An axial extensometer was attached to all specimens to measure tensile strain over a gage length of $50 \mathrm{~mm}$.

Some interlaminar shear (ILSS) tests were also performed on glass/acrylic $0 / 90^{\circ}$ specimens according to ASTM D2344, at a loading rate of $2 \mathrm{~mm} /$ minute on samples $15 \mathrm{~mm}$ wide and with a supported length of $15 \mathrm{~mm}$.

\section{Results}

\section{Weight gain kinetics}

Figure 1 shows the weight gains for the unreinforced resin coupons. The measurements for the three coupons at each temperature are very similar. Table 3 shows diffusion coefficients and saturation weights assuming Fickian diffusion.

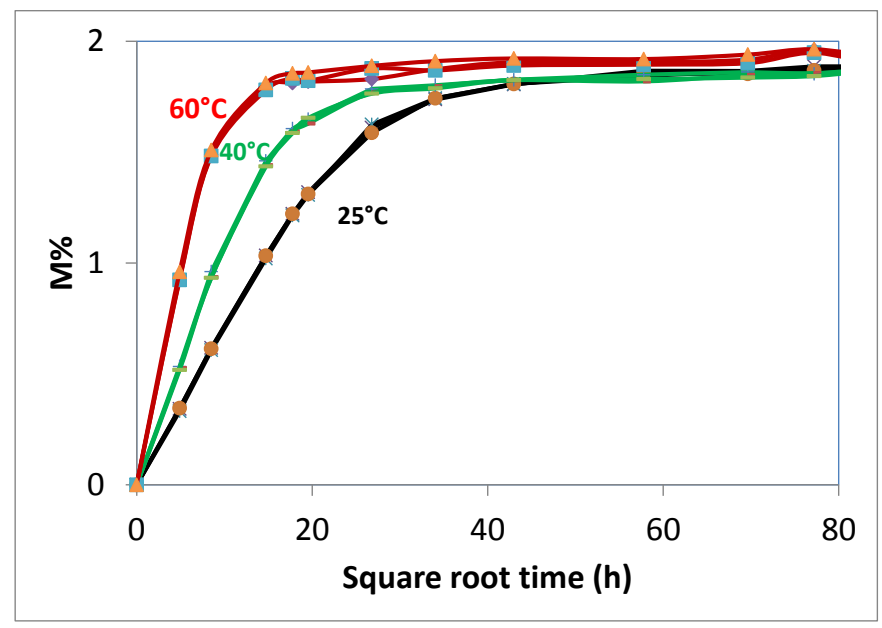

Figure 1. Weight gains in sea water for acrylic matrix resin, 3 coupons at each temperature.

\begin{tabular}{|l|c|c|c|}
\hline Material & Temperature, ${ }^{\circ} \mathrm{C}$ & Ms, \% & $\begin{array}{c}\text { Diffusion coefficient, } \\
\times 10^{-12} \mathrm{~m}^{2} / \mathrm{s}\end{array}$ \\
\hline Resin & 25 & $1.87(0.02)$ & 0.55 \\
& 40 & $1.85(0.02)$ & 1.39 \\
& 60 & $1.90(0.04)$ & 4.23 \\
\hline
\end{tabular}

Table 3. Weight gain characteristics of unreinforced acrylic.

Figure 2 shows a comparison between the weight gains of the resin and the two composites at $60^{\circ} \mathrm{C}$, plotted versus square root of time normalized by the coupon thickness. The carbon composite $\left( \pm 45^{\circ}\right.$ coupons) appears to saturate at around $0.8 \%$ by weight. The glass composite appears to show an initial plateau around $0.7 \%$ after 2 months in water, but the weight then increases again, and when the last points were taken after 18 months they are stable at around $1 \%$.

This plot suggests that water is not only entering the resin but that another mechanism is also taking place. This will be discussed further below. 


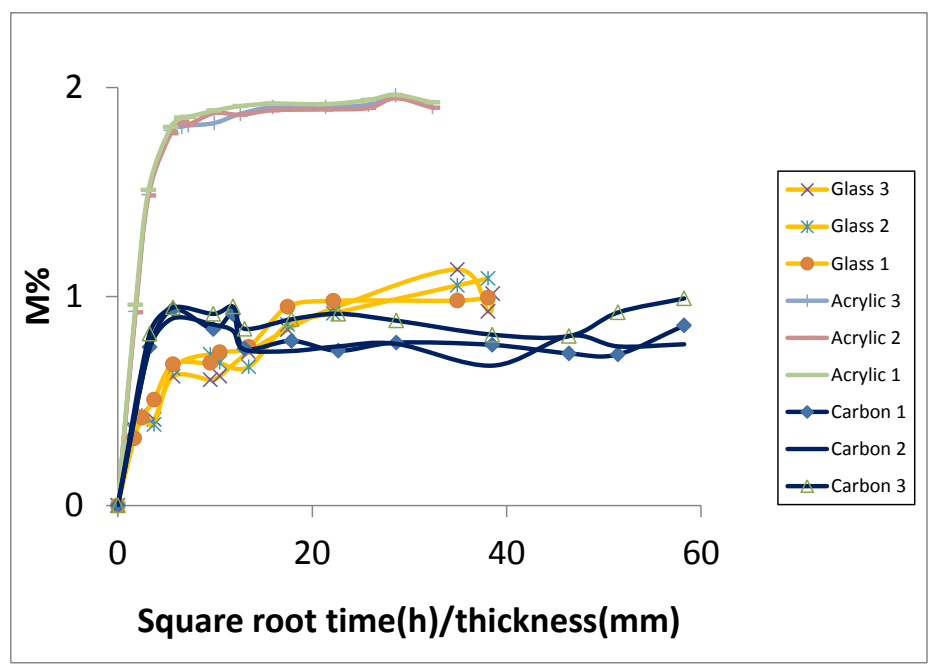

Figure 2. Comparison between resin and composite weight gains during sea water immersion at $60^{\circ} \mathrm{C}$.

\section{Mechanical properties}

a) Unreinforced acrylic

Figure 3 shows the results from tensile tests on wet and dry acrylic samples after immersion, plotted versus specimen weight gain. Figure $3 a$ shows modulus, Figure $3 b$ tensile strength and Figure $3 \mathrm{c}$ failure strain. The points correspond to tests after different immersion times at 25,40 and $60^{\circ} \mathrm{C}$. At these three temperatures the material is saturated with sea water after about 77, 30 and 14 days respectively. Thus for the tests after longer immersions to 77 and 365 days only the time in water is changing, the amount of water remains constant at around $2 \%$. Figure 4 shows all the strength results versus immersion time, together with strengths measured on specimens aged at $60^{\circ} \mathrm{C}$ which we dried to constant weight before testing.

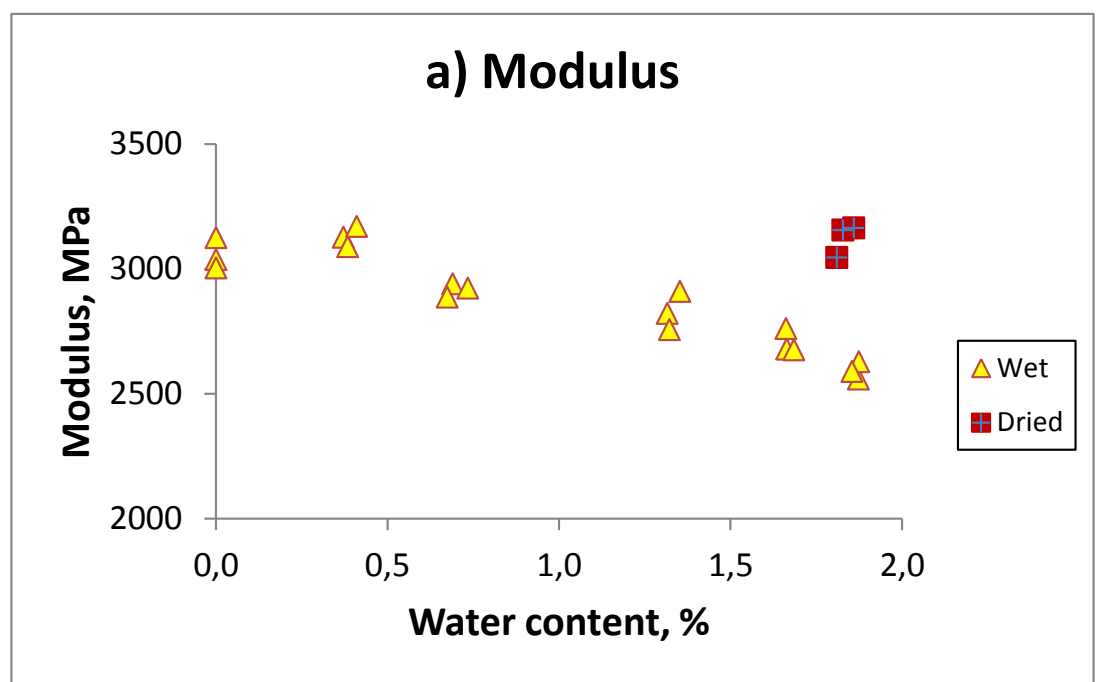




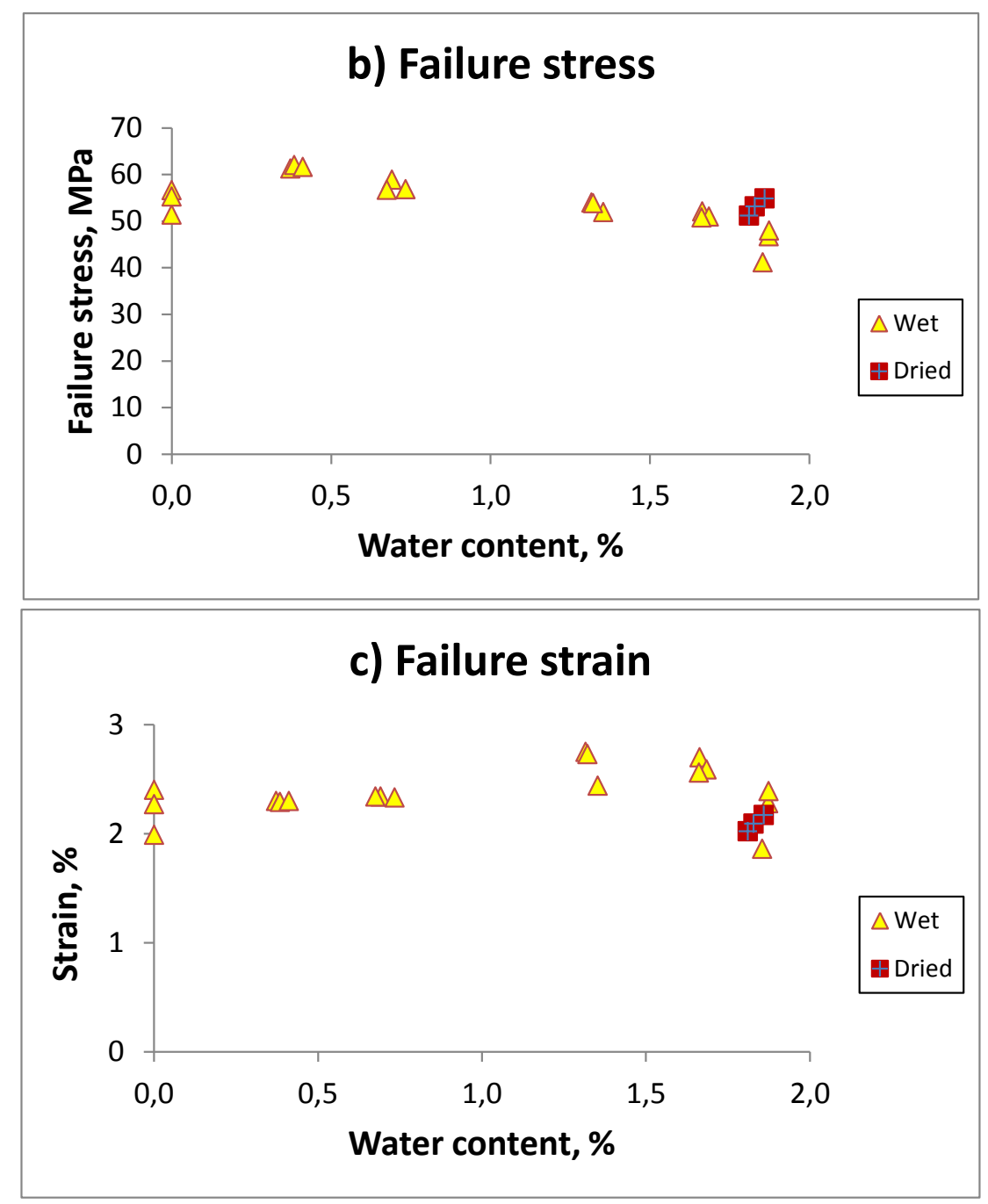

Figure 3. Tensile properties of acrylic versus water content for sea water immersion, all data points.

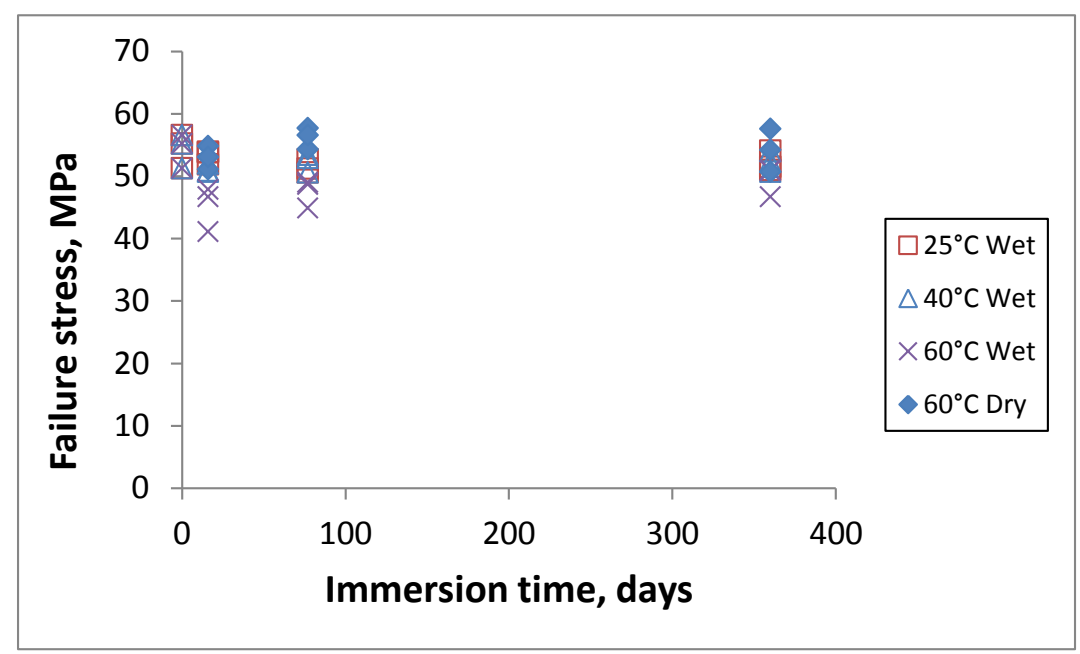

Figure 4. Acrylic resin tensile failure stress after aging in sea water to different times at 3 temperatures, all samples saturated with water from 77 days on. 
It is apparent from the results in Figures 3 and 4 that while the polymer properties do drop by up to $20 \%$ with water ingress, after saturation they are quite stable. In addition the values are quite reversible after drying, suggesting that the main mechanism is plasticization.

b) Glass/acrylic composite

Figure 5 shows examples of stress-strain plots for the glass/acrylic composites loaded in the fibre and $45^{\circ}$ directions after different immersion times. For both cases while modulus drops a little, failure stress and yield stress drop significantly.
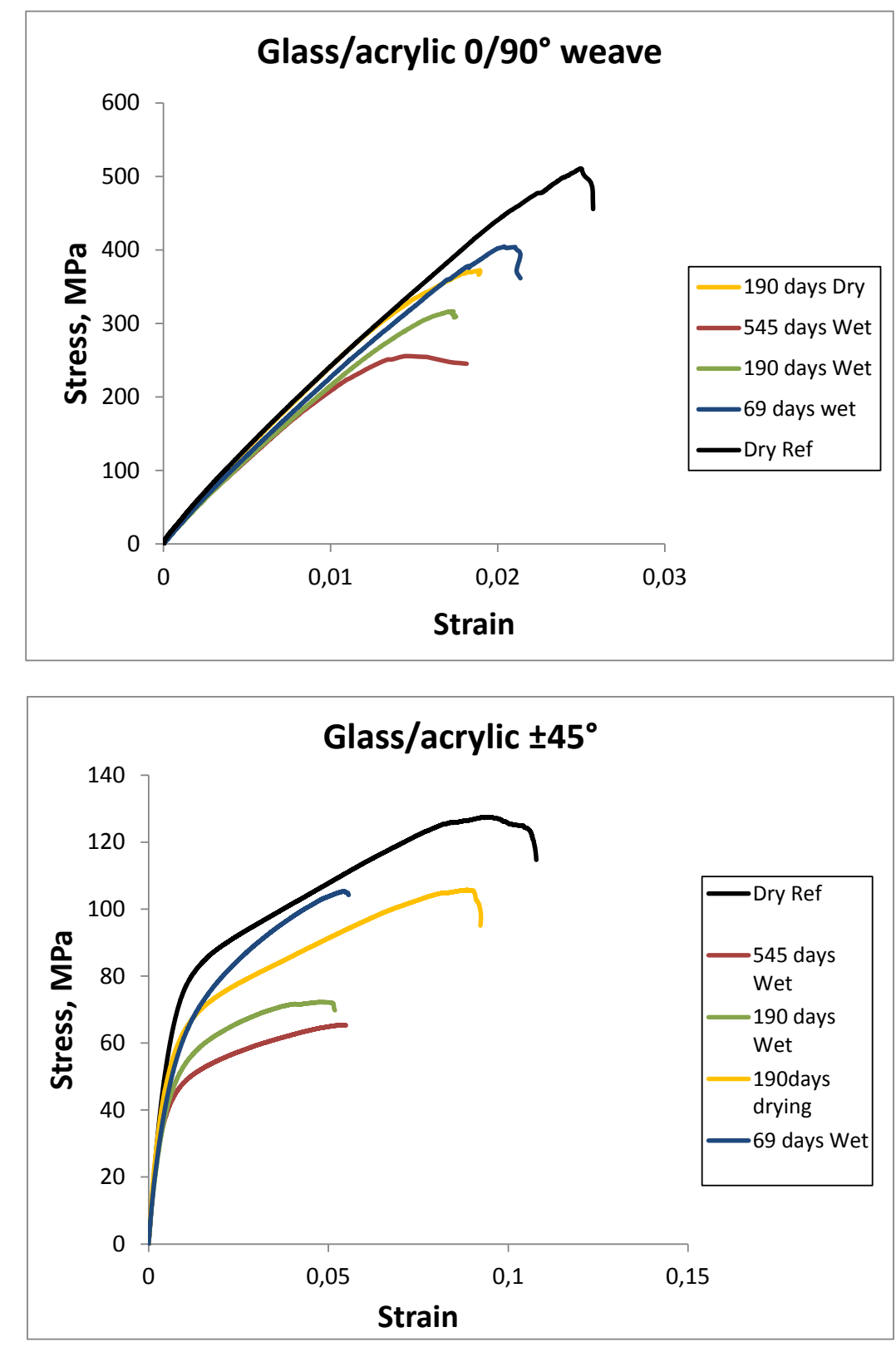

Figure 5. Glass/acrylic. Examples of stress-strain plots, influence of immersion time.

In order to examine to what extent this loss in properties is reversible, Figure 5 also includes plots from tests before and after drying on specimens aged for 190 days. These clearly indicate only a partial recovery after drying. 
Figure 6 shows the test results for both sets of glass/acrylic tensile specimens, tested wet and after drying.
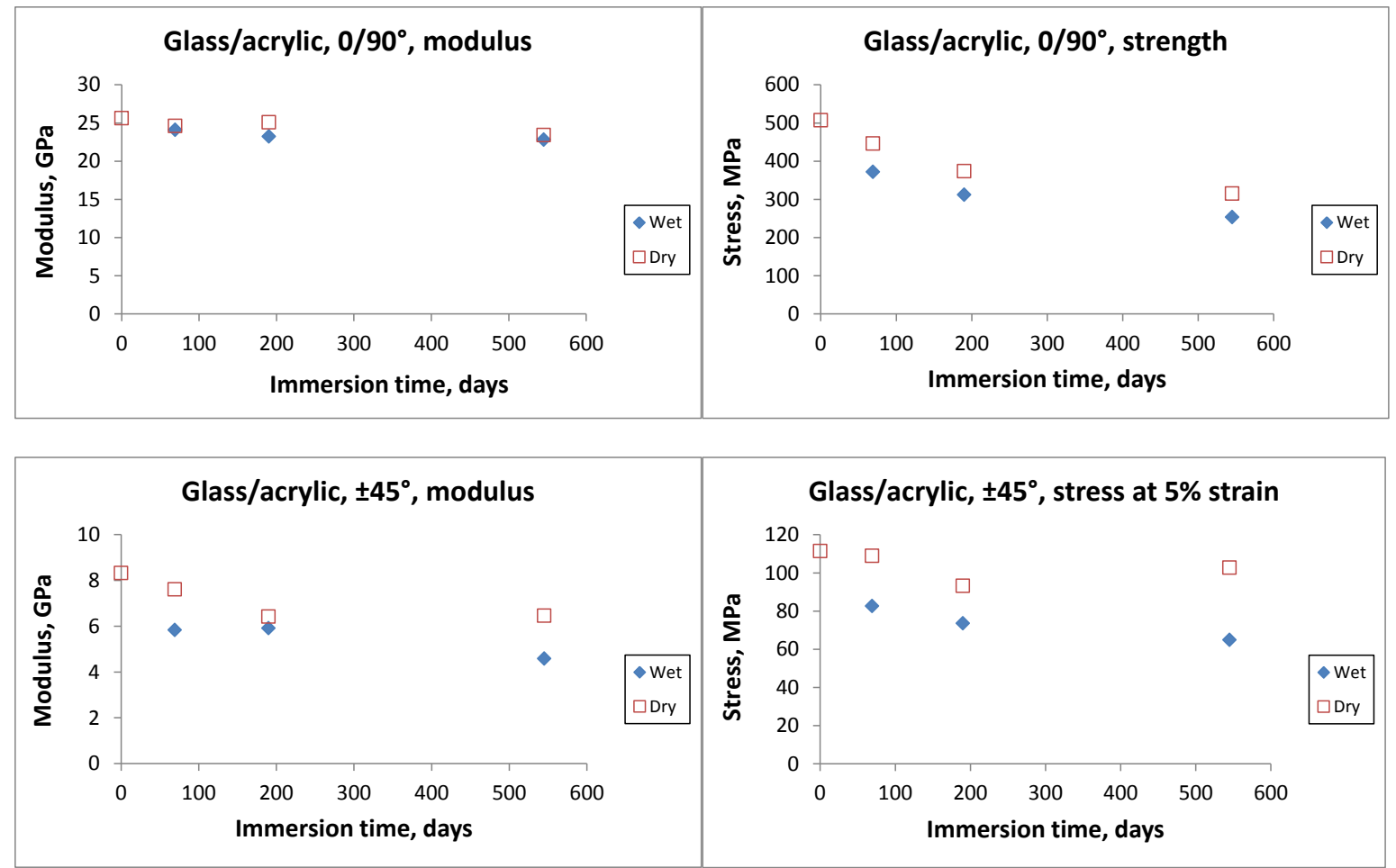

Figure 6. Results from tensile testing of glass/acrylic composites, modulus and strength. Mean values.

It is apparent from these results that this glass fibre/acrylic resin is sensitive to prolonged aging in sea water, but that the strength reductions are at least partially recovered after drying.

c) Carbon/acrylic composites

Figure 7 shows examples of stress-strain plots for the carbon/acrylic composites tested before aging and after immersion for one year in $60^{\circ} \mathrm{C}$ seawater. There is no significant difference in the response of quadriaxial specimens tested in the $0^{\circ}$ fibre direction. However, for the $\pm 45^{\circ}$ specimens the yield stress drops by about $20 \%$ after one year. After drying the initial properties are largely restored, suggesting that it is a plasticization of the wet matrix which is responsible for the drop here. 

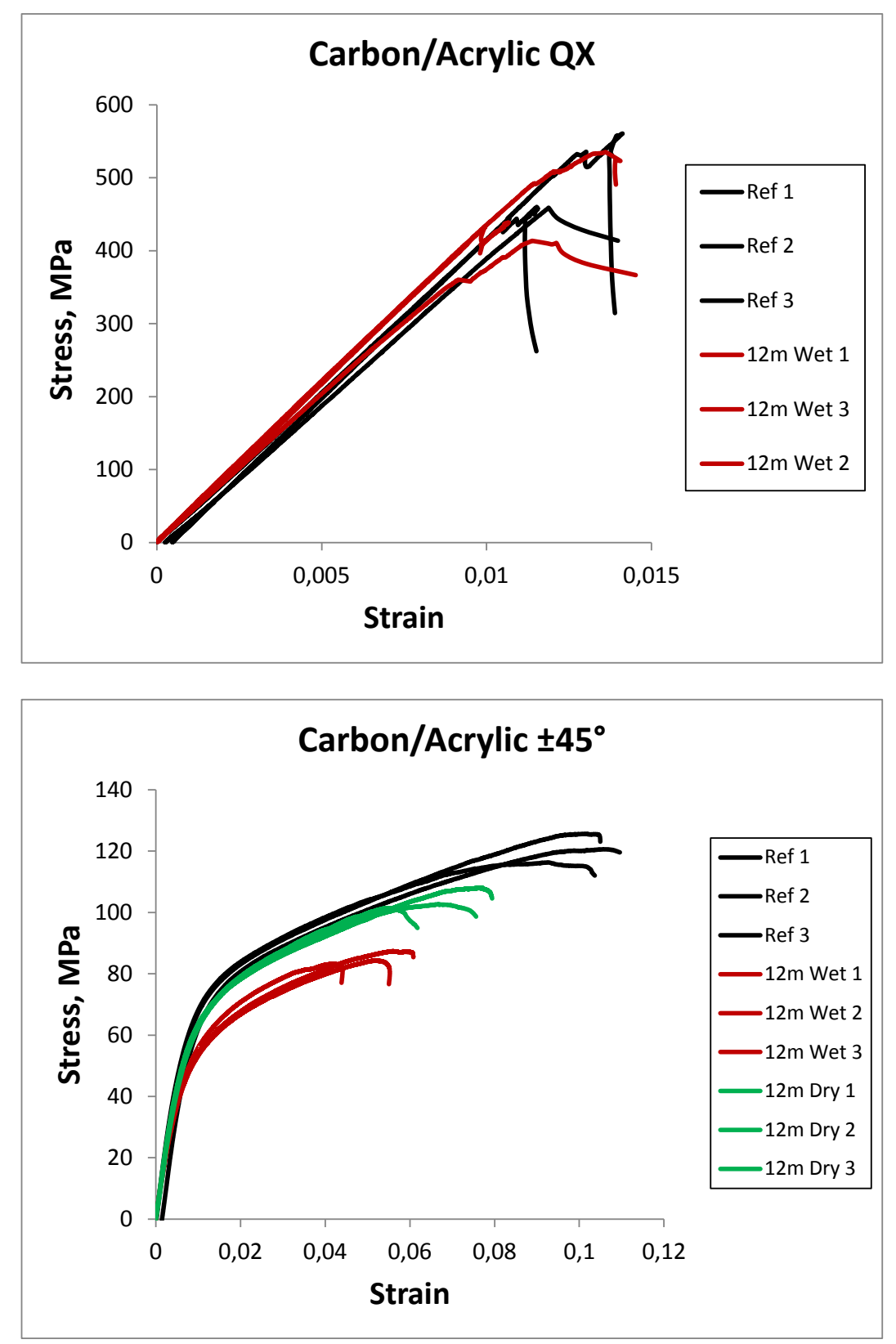

Figure 7. Carbon/acrylic. Examples of stress-strain plots, influence of immersion time and drying. Figure 8 shows the modulus and strength test results for carbon/acrylic tensile specimens wet and dry.

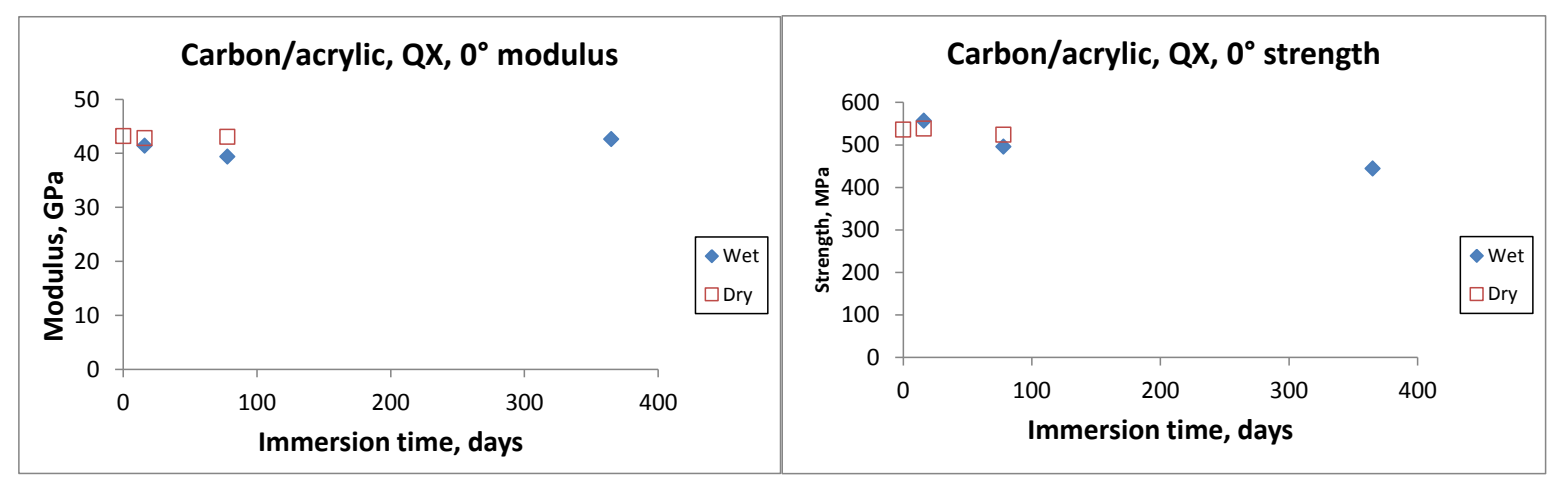



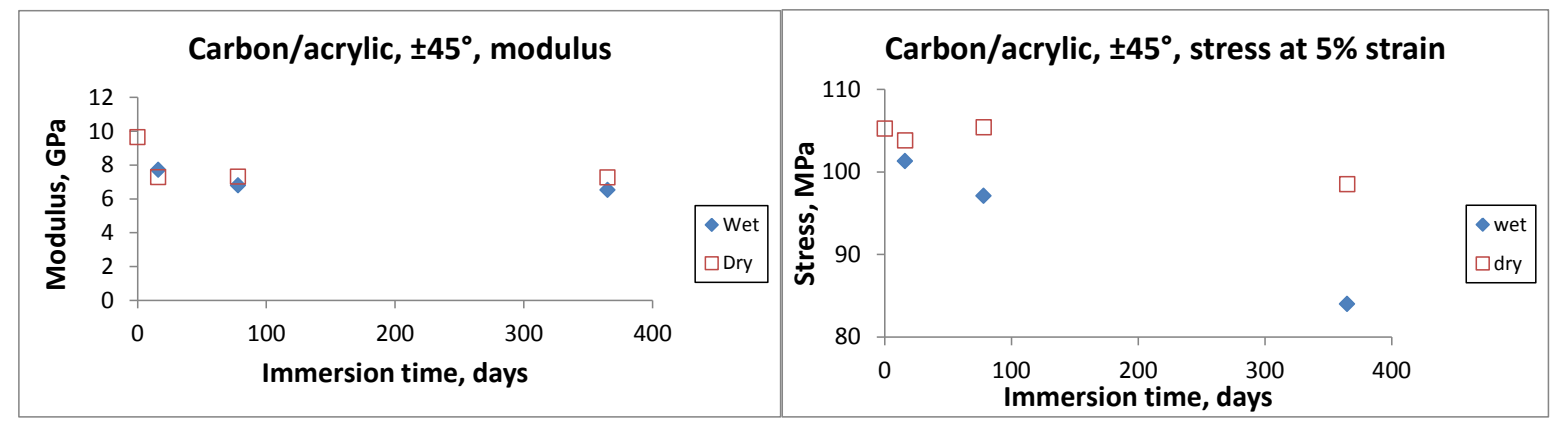

Figure 8. Carbon/acrylic composites, mean modulus and strength after immersion, QX and $\pm 45^{\circ}$ specimens. (Note expanded scale for $\pm 45^{\circ}$ stress at $5 \%$ strain plot).

These figures each show mean values from 3 specimens. In order to provide an indication of scatter Table 4 provides the measured values for the specimens tested after one year in seawater at 25, 40 and $60^{\circ} \mathrm{C}$. In this case four or five specimens were tested at each condition, so standard deviations could be calculated.

\begin{tabular}{|l|c|c|c|c|}
\hline & Reference, Dry & 1 year $25^{\circ} \mathrm{C}$ & 1 year $40^{\circ} \mathrm{C}$ & 1 year $60^{\circ} \mathrm{C}$ \\
\hline QX Modulus (GPa) & $43.2(4.8)$ & $46.4(2.9)$ & $45.8(2.5)$ & $42.6(1.7)$ \\
\hline QX Strength (MPa) & $536(98)$ & $502(90)$ & $598(32)$ & $444(62)$ \\
\hline $45^{\circ}$ Modulus (GPa) & $9.7(0.83)$ & $6.4(0.2)$ & $6.6(0.2)$ & $6.0(0.1)$ \\
\hline $45^{\circ} 5 \%$ stress (MPa) & $105(5)$ & $93(2)$ & $97(4)$ & $84(1)$ \\
\hline
\end{tabular}

Table 4. Variability. Measured mean values for dry reference and after one year immersion at 3 temperatures, carbon/acrylic, tested wet. (Standard deviations in brackets).

d) Summary of mechanical properties after aging

Table 5 summarizes the changes in properties of the five materials after the longest immersion period in $60^{\circ} \mathrm{C}$ sea water ( 12 months for the resin and carbon composites, 18 months for the glass fibre composites). For $45^{\circ}$ specimens strength is taken to be stress at $5 \%$ axial strain.

\begin{tabular}{|l|c|c|c|c|c|}
\hline & $\begin{array}{c}\text { Immersion } \\
\text { Duration }\end{array}$ & $\begin{array}{c}\text { Modulus } \\
\text { wet }\end{array}$ & $\begin{array}{c}\text { Modulus } \\
\text { after drying }\end{array}$ & $\begin{array}{c}\text { Strength } \\
\text { wet }\end{array}$ & $\begin{array}{c}\text { Strength } \\
\text { after drying }\end{array}$ \\
\hline Acrylic Resin & $12 \mathrm{~m}$ & $85 \%$ & $102 \%$ & $83 \%$ & $97 \%$ \\
\hline Glass $0 / 90^{\circ}$ & $18 \mathrm{~m}$ & $89 \%$ & $91 \%$ & $50 \%$ & $62 \%$ \\
\hline Glass $\pm 45^{\circ}$ & $18 \mathrm{~m}$ & $60 \%$ & $78 \%$ & $58 \%$ & $92 \%$ \\
\hline Carbon QX & $12 \mathrm{~m}$ & $99 \%$ & - & $86 \%$ & - \\
\hline Carbon $\pm 45^{\circ}$ & $12 \mathrm{~m}$ & $68 \%$ & $87 \%$ & $80 \%$ & $94 \%$ \\
\hline
\end{tabular}

Table 5. Percentage retention of tensile properties after immersion in seawater at $60^{\circ} \mathrm{C}$, acrylic resin and composites, with respect to unaged values (at least 3 tests per condition).

\section{Discussion}

The results in the previous section raise a number of questions about the performance of acrylic matrix composites in a marine environment. First, how do water diffusion kinetics in these materials 
compare to those in currently used matrix polymers ? Second, how does the property retention of these materials compare with traditional composites ? And finally, what are the degradation mechanisms which develop in these glass and carbon fibre reinforced acrylic composites?

\section{$\underline{\text { Diffusion kinetics }}$}

The values in Table 3 for diffusion coefficients are compared to values for other matrix resins in Table 6. It is apparent that the weight gains at saturation are similar and diffusion coefficients are a little faster than the epoxy and slower than the polyester. However, these parameters are strongly dependent on resin chemistry, curing and aging conditions, and higher or lower values could be found in the literature.

\begin{tabular}{|l|c|c|c|c|}
\hline Matrix & Condition & $\mathrm{Ms}, \%$ & $\mathrm{D}, \mathrm{m}^{2} / \mathrm{s}, 10^{-12}$ & Reference \\
\hline Acrylic & $25^{\circ} \mathrm{C} \mathrm{SW}$ & $1.87(0.02)$ & 0.55 & Present \\
& $40^{\circ} \mathrm{C} \mathrm{SW}$ & $1.85(0.02)$ & 1.39 & work \\
& $60^{\circ} \mathrm{C} \mathrm{SW}$ & $1.90(0.04)$ & 4.23 & \\
& $65^{\circ} \mathrm{C} 75 \% \mathrm{RH}$ & 1.19 & 5.1 & {$[20]$} \\
& & & & \\
\hline Polyester & $30^{\circ} \mathrm{C} \mathrm{W}$ & 3.95 & 1.3 & {$[21]$} \\
Isophthalic & $45^{\circ} \mathrm{C} \mathrm{W}$ & 3.90 & 3.5 & {$[21]$} \\
& $60^{\circ} \mathrm{C} \mathrm{W}$ & 3.70 & 8.6 & {$[21]$} \\
\hline Epoxy & $20^{\circ} \mathrm{C} \mathrm{SW}$ & 2.5 & 0.07 & {$[22]$} \\
& $40^{\circ} \mathrm{C} \mathrm{SW}$ & 2.5 & 0.32 & {$[22]$} \\
& $60^{\circ} \mathrm{C} \mathrm{SW}$ & 2.5 & 1.77 & {$[22]$} \\
\hline
\end{tabular}

Table 6. Matrix resin diffusion coefficients (SW: Seawater, RH: Relative Humidity, W: Unspecified water)

With respect to the composites, the non-Fickian behavior observed in Figure 2 makes direct comparisons delicate, but it is the matrix which dominates composite diffusion, and the composite weight gains are coherent with the amount of matrix present.

\section{Property retention after immersion}

The three types of material (unreinforced resin, glass fibre and carbon fibre reinforced composites) will be examined separately. First, Figure 9 shows a comparison for tensile tests between values for unreinforced acrylic and similar tests performed on a commonly used commercial marine epoxy matrix resin, for which the weight gain at saturation exceeds 4\% [23]. This indicates significantly better strength retention for the acrylic resin. 


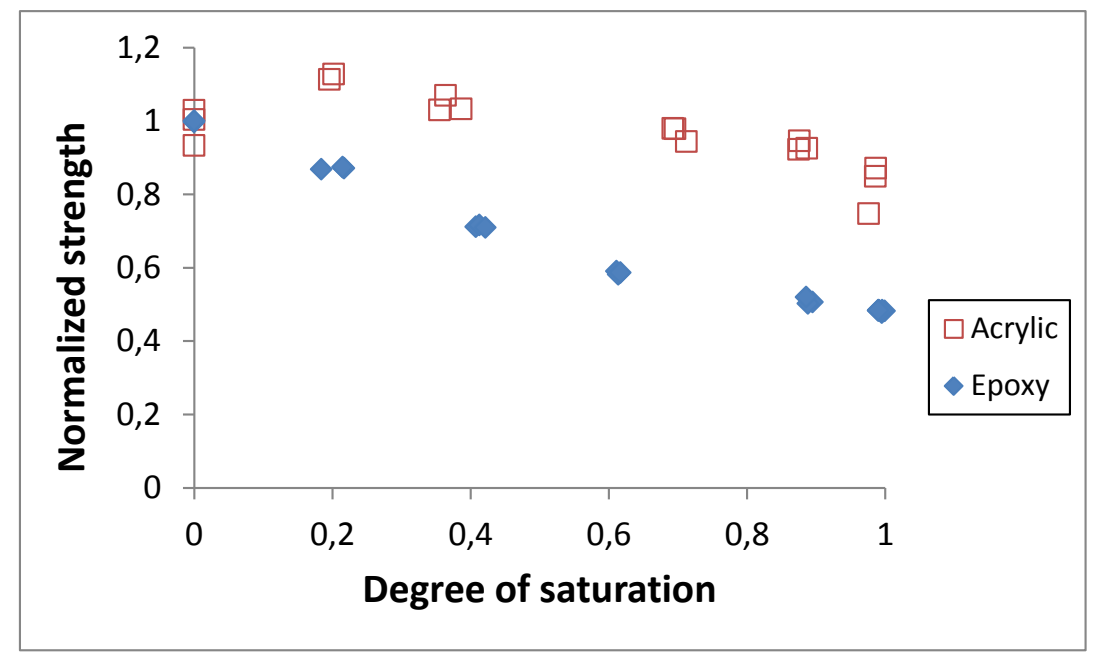

Figure 9. Tensile property retention versus degree of saturation with sea water, acrylic and epoxy matrix resins.

With respect to property losses for glass fibre reinforced composites after immersion, Smith indicated in 1991 that the maximum drop in both tensile modulus and strength in E glass/polyester laminates cut from boat hulls was around $20 \%$ [1].

Published values from various laboratory studies, in which considerably more severe conditions are often applied to accelerate aging, are also available. However, it is not straightforward to compare results directly for several reasons. First, the aging conditions are often different, various media including relative humidity tap water, distilled water, artificial seawater and natural seawater are employed, and different water temperatures are used to accelerate aging. Second, flexural tests rather than tension are often used to follow property changes and these tests are very sensitive to surface changes as water enters surface layers first. And third, the materials themselves are not always directly comparable; as they contain higher or lower fibre contents and specific reinforcements with different lay-ups, weave patterns or stitching threads. Nevertheless, some data have been found for comparison, from a study by Pritchard and Speake [21] who provided empirical expressions to relate strength loss in polyester composites to water content. Figure 10 shows two examples from that work, which allow changes in the glass/acrylic modulus and strength values after saturation to be compare to those for a glass reinforced isophthalic polyester used in boatbuilding and produced by hand lay-up. From these data it appears that the infused glass/acrylic offers better property retention than the classic boatbuilding material. 


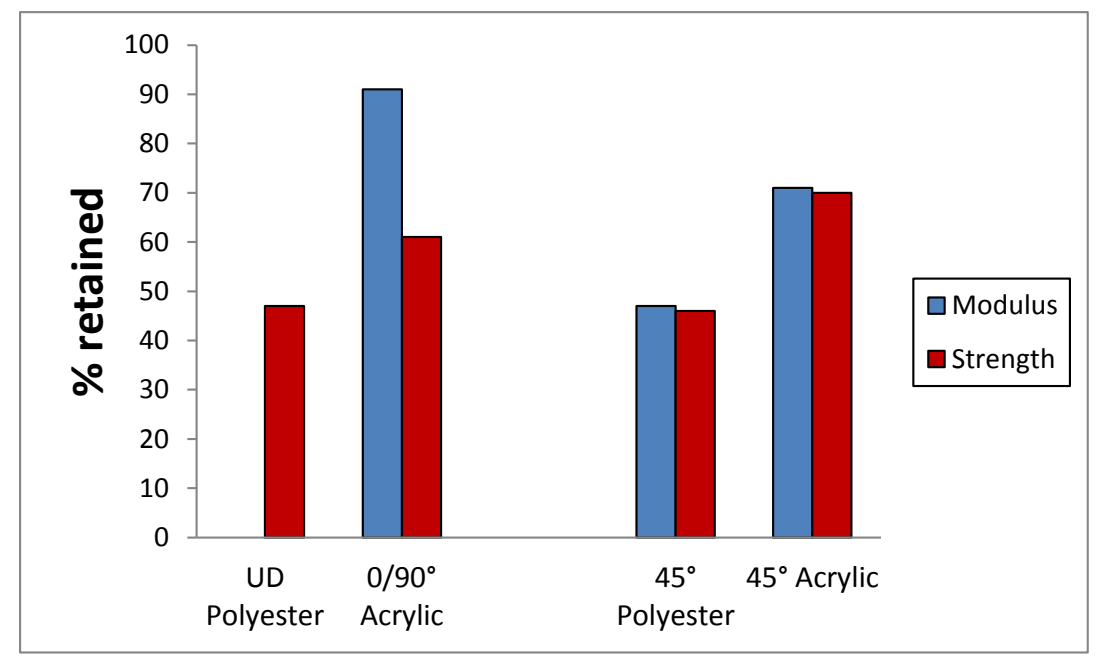

Figure 10. Comparison between glass/acrylic and glass/polyester, stiffness (blue) and strength (red) retained after saturation in water, expressed as a percentage of dry test values [21].

Concerning carbon/epoxy composites, Tual et al [23] recently published results from tests on both unidirectional and $\pm 45^{\circ}$ carbon/epoxy composites produced by RTM and infusion (unfortunately quasi-isotropic epoxy matrix laminates were not tested), both based on the same epoxy resin matrix as the one used for comparison in Figure 9. These were saturated with natural seawater in the same aging tanks as those used for the present study, and then tested wet on the same test machines as those used in the present study. Figure 11 shows the influence of saturating the matrix with seawater on the tensile properties, compared to the acrylic quasi-isotropic and $\pm 45^{\circ}$ specimens. The response is quite similar for both materials, for these fibre dominated and matrix-dominated tests, with at least $70 \%$ retention of properties.

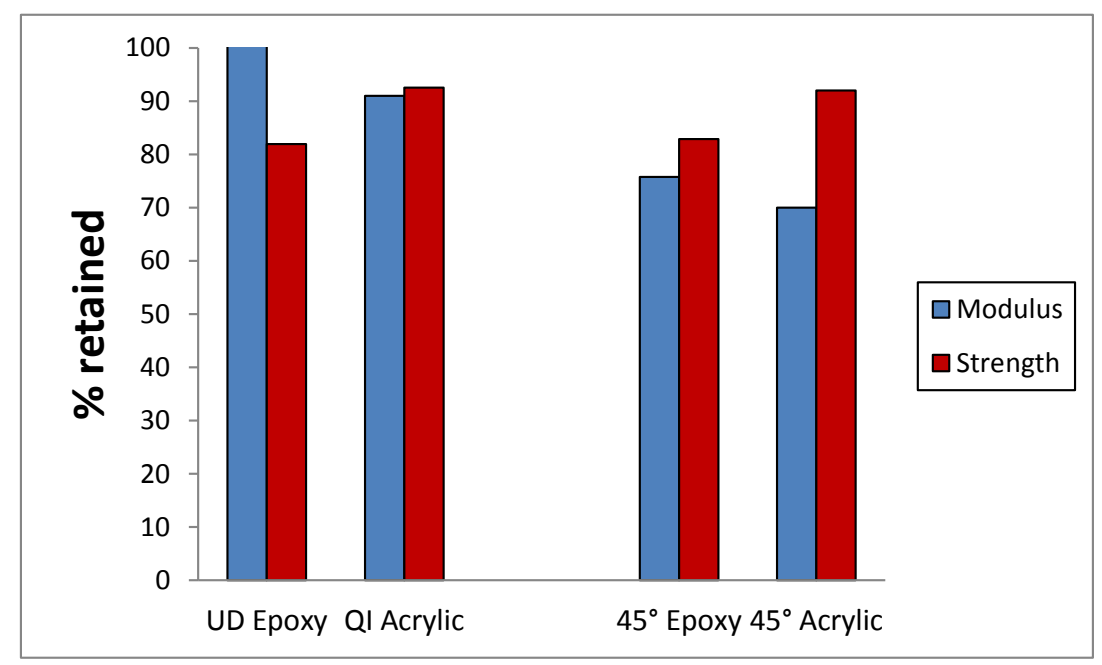

Figure 11. Comparison between carbon/epoxy and carbon/acrylic, percentage of stiffness (blue) and strength (red) retained after saturation in seawater with respect to dry test values [23].

\section{Degradation mechanisms}

Recovery of tensile property drops after drying for unreinforced acrylic and carbon fibre reinforced composite specimens suggests that matrix plasticization by water is the main mechanism present. For the glass fibre reinforced composites, drying after immersion did not restore properties, so at 
least one permanent damage mechanism is occurring. As there is no reason to believe that the matrix is further degraded in these specimens than in those reinforced with carbon fibres, it is either the fibre/matrix interface or the glass fibres which have been affected by water. Figure 12 shows fracture surfaces from tensile tests on $\pm 45^{\circ}$ specimens in the unaged state and after 18 months' immersion. While images at this scale show only a small region these clearly show cleaner fibres after aging.
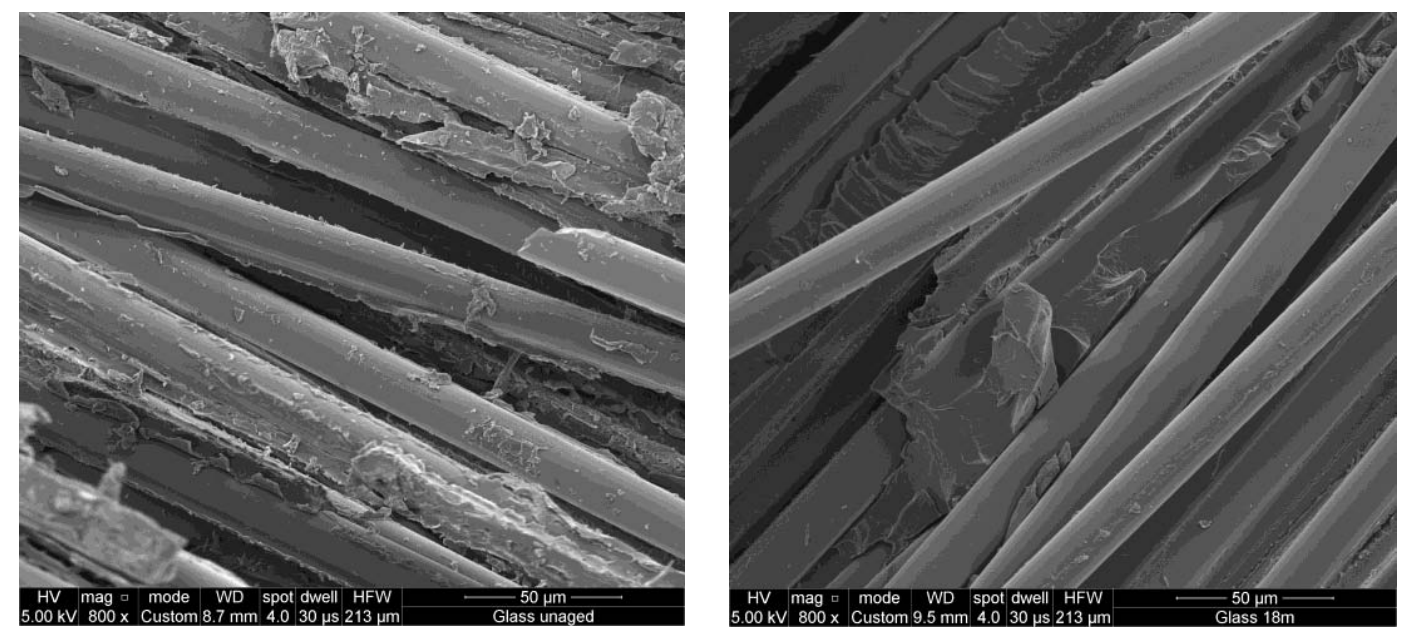

Figure 12. SEM images, fracture surfaces glass/acrylic $\pm 45^{\circ}$ tensile specimens, (left) unaged and (right) after 18 months' immersion in seawater at $60^{\circ} \mathrm{C}$.

Glass/acrylic tensile specimens were not aged at temperatures below $60^{\circ} \mathrm{C}$, but In order to examine whether degradation was also present after immersion at lower temperatures, ILSS specimens have been taken from the weight gain coupons immersed for 18 months at different temperatures, and tested wet. Figure 13 shows the results.

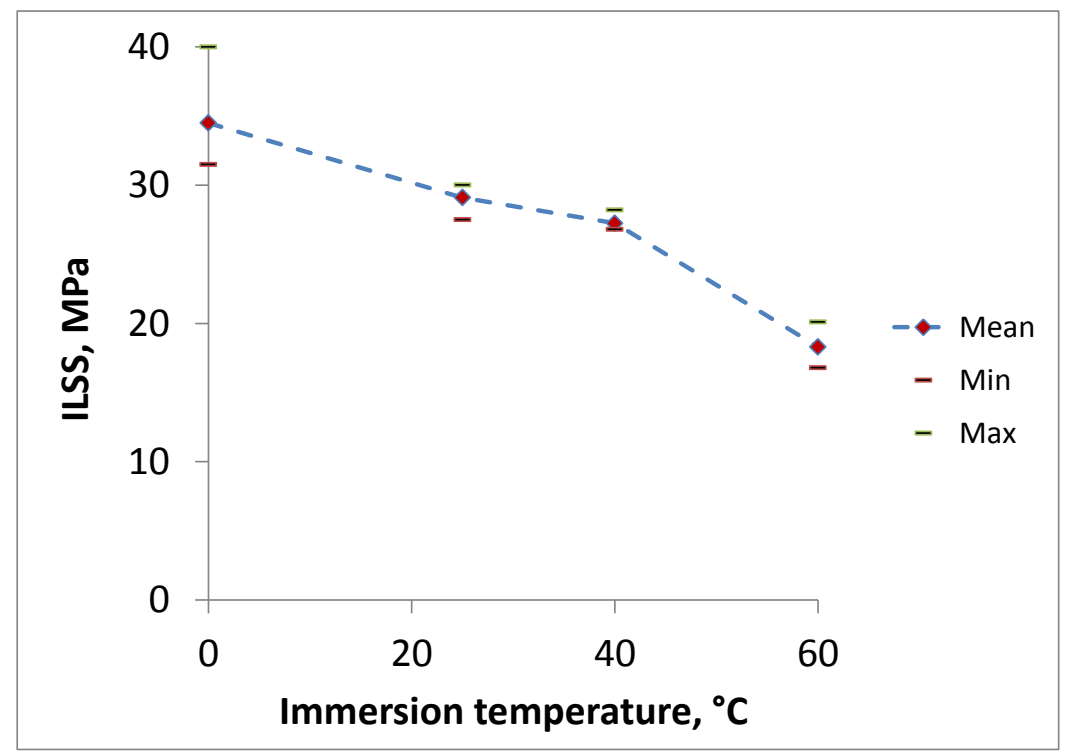

Figure 13. ILSS results for glass/acrylic unaged reference (on y-axis) and tested wet after 18 months' immersion at 25,40 and $60^{\circ} \mathrm{C}$.

There is clearly a significant reduction in interlaminar shear strength after aging, which increases with increasing water temperature, but even after 18 months at $40^{\circ} \mathrm{C}$ a $21 \%$ drop is measured. 


\section{Conclusions}

This study has shown that liquid infusable thermoplastic acrylic resin is stable in seawater when immersed at temperatures up to $60^{\circ} \mathrm{C}$ for up to one year. A small drop in properties was noted, lower than for an epoxy resin used today as a matrix for composite structures, and this was found to be fully recoverable after drying.

The glass reinforcement used in the composites tested here was not optimized for an acrylic matrix and some fibre/matrix interface degradation was observed after aging at $60^{\circ} \mathrm{C}$ in seawater. Specific glass sizings are currently being developed for acrylic composites.

Carbon fibre reinforced acrylic composites showed little change in tensile properties after aging at $60^{\circ} \mathrm{C}$ for up to one year. A small drop in properties of $\pm 45^{\circ}$ composites was recovered after drying.

These first results indicate that acrylic resins show satisfactory durability for marine applications. Further study, particularly of fatigue behavior, is needed. However, the potential to recycle these composites which have been infused by traditional manufacturing methods makes them potentially very attractive for marine structures.

\section{Acknowledgements}

The authors are grateful to Pierre Gérard and Sebastien Taillemite of Arkema, for the gift of unreinforced and carbon fibre reinforced acrylic specimens, and for helpful discussions.

\section{References}

[1] Smith CS, (1990), Design of Marine Structures in Composite Materials, Elsevier.

[2] Mouritz, A, Gellert, E, Burchill, P and Challis, K, (2001), 'Review of advanced composite structures for naval ships and submarines', Composite Structures, 53, no. 1, pp. 21-41.

[3] Shenoi RA, Wellicome JF, (1993), Composite materials in Maritime Structures, Cambridge Ocean Technology series.

[4] Barblou P, APER (Association pour la Plaisance Eco-Responsable), Network of dismantling recreational craft in France, presented at "The Future of Yacht Recycling", METS 2015, 16 November (2015), Amsterdam.

[5] Smith R (Editor), Biodegradable polymers for industrial applications, CRC Woodhead Publishers, (2005).

[6] Arkema website, http://www.arkema.com/en/innovation/arkema-sailing/arkema-boats/mini-650-prototype/

[7] Josserand C, Schirrer R, Davies P, Influence of water on crack propagation in poly methyl methacrylate: craze stress and craze fibril lifetime J. Materials Science, 30 (1995) 1772-1780 
[8] Mouritz AP, Gibson AG, Fire Properties of Polymer Composite Materials, Springer publishers, (2006), p34.

[9] Manfredi LB, Rodrıguez ES, Wladyka-Przybylak M, Vazquez A, Thermal degradation and fire resistance of unsaturated polyester, modified acrylic resins and their composites with natural fibres, Polymer Degradation and Stability 91 (2006) 255-261

[10] Kalachandra S, Turner DT, Water sorption of plasticized denture acrylic lining materials, Dental Materials, May (1989), 161-164

[11] Arima T, Murata $\mathrm{H}$, and Hamada T, Properties of highly cross-linked auto-polymerizing reline acrylic resins, J. Prosthetic Dentistry, January (1995), 55-59

[12] Weitsman YJ. (2012). Fluid effects in polymers and polymeric composites. Springer.

[13] Davies P, Rajapakse Y. Editors, (2014), Durability of composites in a marine environment, Springer

[14] Gutierrez J, LeLay F, Hoarau P, A study of the aging of glass fibre-resin composites in a marine environment, in Proceedings Nautical Construction with composite materials, editors P. Davies, L. Lemoine, Paris, (1992, IFREMER) Publication ISSN-0761-3989, pp 338-346

[15] Gellert EP, Turley DM, Seawater immersion ageing of glass-fibre reinforced polymer laminates for marine applications, Composites Part A, 30, Issue 11, November (1999), 1259-1265

[16] Davies P, Mazeas F, Casari P, Sea water aging of glass reinforced composites: Shear behaviour and Damage modeling, Journal of Composite Materials 35, No. 15, (2001), pp1343-1372

[17] Kootsookos A, Mouritz AP, Seawater durability of glass- and carbon-polymer composites, Composites Science and Technology 64 (2004) 1503-1511

[18] Marouani S, Curtil L, Hamelin P, Ageing of carbon/epoxy and carbon/vinylester composites used in the reinforcement and/or the repair of civil engineering structures, Composites Part B:

Engineering, Volume 43, Issue 4, June (2012), 2020-2030

[19] Siriruk A, Penumadu D, Degradation in fatigue behavior of carbon fiber-vinyl ester based composites due to sea environment, Composites Part B: Engineering, Volume 61, May (2014), 94-98

[20] Lee S-B, Rockett TJ, Hoffman RD, Interactions of water with unsaturated polyester, vinyl ester and acrylic resins, Polymer, (1992), 33, 17 3691-7

[21] Pritchard G, Speake SD, The use of water absorption kinetic data to predict laminate property changes, Composites, 18, 3, (1987), 227-232

[22] Boisseau A, Davies P, Thiebaud F, Sea Water Ageing of Composites for Ocean Energy Conversion Systems: Influence of Glass Fibre Type on Static Behaviour, Appl Compos Mater (2012) 19, 459-473

[23] Tual N, Carrere N, Davies P, Bonnemains T, Lolive E, Characterization of sea water ageing effects on mechanical properties of carbon/epoxy composites for tidal turbine blades, Composites: Part A 78 (2015) 380-389. 